\title{
Tuberculosis-Associated Chylothorax: Case Report and Systematic Review of the Literature
}

\author{
Srinivas Rajagopala Roopa Kancherla Ramanathan Palaniappan Ramanathan \\ Department of Pulmonary Medicine, PSG Institute of Medical Sciences and Research, Peelamedu, Coimbatore, India
}

\section{Established Facts}

- Trauma is the most common cause of chylothorax.

- Tuberculosis (TB) is described as a cause of nontraumatic chylothorax, but several large series do not include any patients with TB-chylothorax.

\section{Novel Insights}

- $\mathrm{TB}$ is a very rare cause of chylothorax with only 37 cases reported in the literature.

- TB-chylothorax developed subsequent to the diagnosis of TB in $27.8 \%(10 / 36)$ of the patients after a median of 6.75 weeks (IQR 4-9) while on anti-TB treatment.

- TB-chylothorax developed during an immune reconstitution syndrome in $16.7 \%(6 / 36)$ of the patients, even in immunocompetent ones.

- TB-chylothorax developed in the absence of any mediastinal lymphadenopathy in $45.9 \%$ (17/37) of the patients; $13.5 \%$ (5/37) had isolated tubercular empyema alone.

- TB-chylothorax developed along with chylous ascites in 10.8\% (4/37) of the patients.

- Most patients with TB-chylothorax responded to anti-TB treatment and dietary manipulation alone, and only $17.1 \%(6 / 35)$ needed thoracic duct ligation.

\section{Keywords}

Tuberculosis · Chylothorax · Pleural effusion · Chylomicron

\begin{abstract}
Tuberculosis (TB) is a rare cause of chylothorax. We describe a case and the results of a systematic review of all reported cases of TB-chylothorax. We identified 37 cases of TB-chylothorax. The symptoms at presentation were constitutional (85.7\%; 30/35), dyspnea (60.6\%; 20/33), and cough (54.5\%;
\end{abstract}

18/33). Chylothorax developed subsequent to the diagnosis of TB in $27.8 \%(10 / 36)$ of the patients, after a median of 6.75 weeks (IQR 4-9). Chylothorax developed during an immune reconstitution syndrome (IRS) in 16.7\% (10/36) of the patients, including immunocompetent ones. TB was disseminated in $45.9 \%(17 / 37)$ of the patients at the diagnosis of chylothorax. Chylothorax developed in the absence of any mediastinal lymphadenopathy in $45.9 \%$ (17/37) of the patients; $13.5 \%$ (5/37) had isolated tubercular empyema alone. The diagnosis of TB was established microbiologically in

\section{KARGER}

(C) 2018 S. Karger AG, Basel

E-Mail karger@karger.com

www.karger.com/res
Dr. Srinivas Rajagopala

Department of Pulmonary Medicine

PSG Institute of Medical Sciences and Research

Peelamedu, Coimbatore 641004 (India)

E-Mail visitsrinivasan@ gmail.com 
$72.2 \%(26 / 36)$ and by biopsy alone in $27.8 \%(9 / 36)$ of the patients. Anti-TB treatment (ATT) was administered for a median of 7.57 months (IQR 6-9). Steroids were administered to $22.9 \%(8 / 35)$ of the patients, often for suspected IRS. Thoracic duct ligation and octreotide were required for only $17.1 \%(6 / 35)$ and $8.6 \%(3 / 35)$ of the patients, respectively. In all, $94.4 \%$ (34/36) of the patients had resolution of chylothorax and completed treatment successfully; only $5.6 \%$ (2/36) died. In conclusion, TB-chylothorax may develop without obvious mediastinal lymphadenopathy and be associated with tubercular empyema alone. TB-chylothorax can develop during treatment of TB due to IRS, even in immunocompetent patients. ATT and dietary manipulation are associated with good resolution and low mortality, and duct ligation is needed for only a small minority of patients.

(c) 2018 S. Karger AG, Basel

\section{Introduction}

Tuberculosis (TB) continues to be a global scourge. India has the highest TB burden and accounts for approximately more than one-fifth (21\%) of the global disease burden, with recently revised higher estimates of disease burden $[1,2]$. Chylothorax is characterized by the presence of chyle in the pleural space due to thoracic duct disruption [3, 4]. Accumulation of cholesterol or lecithinglobulin complexes in pleural fluid of long-standing effusions can occur and is described as a pseudochylothorax $[3,5]$. TB is a well-described cause of pseudochylothorax [5]; the association of TB with chylothorax, however, is very rare but has been described. The mechanisms of development of chylothorax in TB (TB-chylothorax), clinical features, radiological findings, mode of diagnosis, and management aspects are unclear.

\section{Case Report}

A 50-year-old gentleman with diabetes mellitus of 5 years duration presented with productive cough for 15 days, intermittent fever, and right-sided pleuritic chest pain of 1-week duration. Chest radiography (Fig. 1, left) confirmed a right-sided pleural effusion, and diagnostic thoracocentesis showed pus-like material; an intercostal tube drain was inserted, and he was referred to this center for persisting purulent drainage from the drain. There was no history of trau$\mathrm{ma}$, anorexia, or weight loss. He did not report any significant illness in his family or contact with TB, did not smoke or drink alcohol, and did not raise pets. The examination showed pallor, pedal pitting ede$\mathrm{ma}$, a regular heart rate of $72 / \mathrm{min}$, and a blood pressure of $120 / 70$ $\mathrm{mm} \mathrm{Hg}$. There was no evidence of alveolopleural fistulae, and the intercostal drain continued to drain $750 \mathrm{~mL} /$ day of whitish fluid.

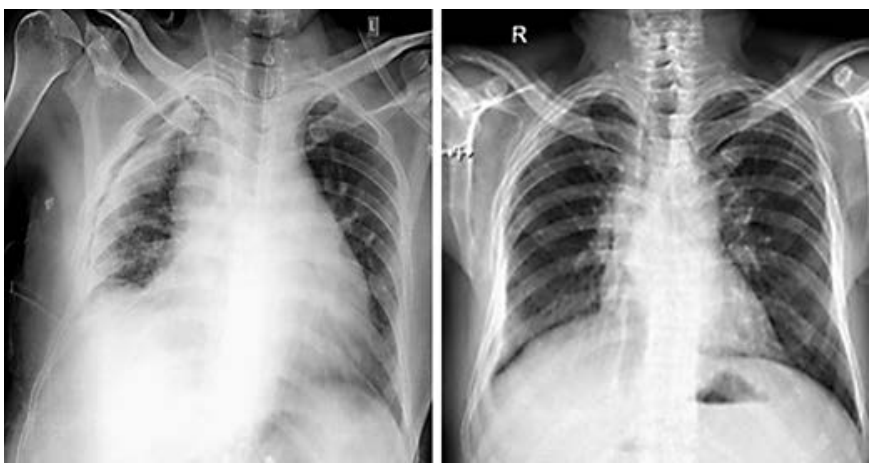

Fig. 1. Left: chest radiograph at diagnosis showing a right pyopneumothorax with pleural thickening and intercostal drain in situ. Right: chest radiograph at completion of anti-tuberculosis treatment showing significant interval resolution with minimal pleural thickening.

Chest radiography showed a right pyopneumothorax (Fig. 1, left). Hemoglobin was at $6.9 \mathrm{~g} / \mathrm{dL}$, with normal leukocyte and platelet counts. Renal function testing showed renal failure with serum creatinine at $9.4 \mathrm{mg} / \mathrm{dL}$ (normal 0.8-1.0). Urine microscopy showed bland sediments without albuminuria. Ultrasound showed a normal kidney size with increased renal cortical echogenicity. Arterial blood gas showed metabolic acidosis ( $\mathrm{pH} 7.25, \mathrm{HCO}_{3} 14$ $\mathrm{mEq} / \mathrm{L}, \mathrm{pCO}_{2} 30 \mathrm{~mm} \mathrm{Hg}$, anion gap $16 \mathrm{mEq} / \mathrm{L}$ ). Fundus examination showed findings consistent with mild nonproliferative diabetic retinopathy. $\mathrm{HbA}_{1 \mathrm{c}}$ was at $9.2 \%$ (normal <6.5). Human immunodeficiency virus (HIV), hepatitis $B$, and hepatitis $C$ tests by enzyme-linked immunosorbent assay were all negative. Two sputum smears were negative for acid-fast bacilli by Ziehl-Neelsen $(\mathrm{ZN})$ staining. Liver function and thyroid function tests were normal. Pleural fluid analysis showed 99\% neutrophils, with sugar $<0.8 \mathrm{mg} / \mathrm{dL}$. Pleural fluid cultures yielded Candida albicans twice; bacterial cultures were sterile, and the $\mathrm{ZN}$ smears of the pleural fluid were negative. Echocardiography showed normal left ventricular function with no valvular abnormalities, and fundoscopy was normal. A diagnosis of candidal empyema was made and fluconazole treatment was started according to sensitivity. Repeat pleural fluid cultures were sterile and showed an exudative (protein $4.1 \mathrm{~g} / \mathrm{dL}, \mathrm{LDH} 321 \mathrm{IU} / \mathrm{mL}$ ), lymphocytic effusion (95\%); however, the patient continued to have persistent drainage of purulentlooking fluid. A pleural fluid biochemical analysis was requested; it showed triglycerides at $135 \mathrm{mg} / \mathrm{dL}$ and cholesterol at $35 \mathrm{mg} / \mathrm{dL}$. Because of diagnostic ambiguity, pleural fluid chylomicron testing was done (Christian Medical College, Vellore, India) and it was strongly positive for chylomicrons. Plain CT of the thorax (Fig. 2, 3) showed significant mediastinal adenopathy with calcification involving the pretracheal, aortopulmonary, bilateral hilar and subcarinal stations. He was planned for endobronchial ultrasoundguided needle aspiration, but, meanwhile, GeneXpert testing of the pleural fluid was positive for Mycobacterium tuberculosis (MTB), and Mycobacterium growth indicator tube cultures of the pleural fluid isolated MTB.

A final diagnosis of poorly controlled diabetes, disseminated TB with right-sided chylothorax complicated by candidal empy- 

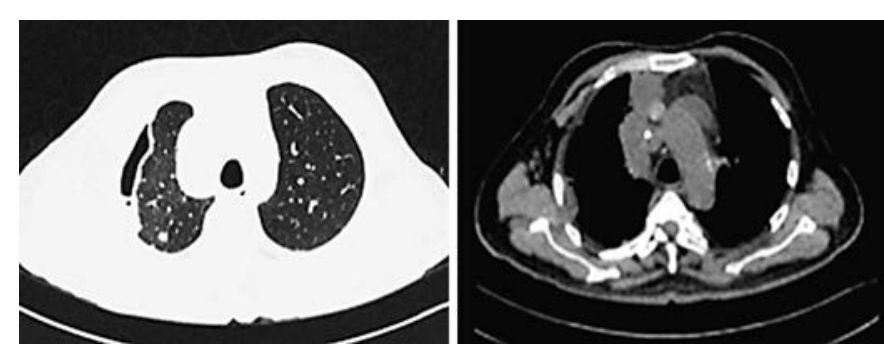

Fig. 2. Plain computed tomography images of the thorax (taken because of acute renal failure) showing moderate pericardial effusion and right mediastinal pleural collection and thickening; significant mediastinal adenopathy (largest: $2.5 \times 2 \mathrm{~cm}$ ) involving the pretracheal, aortopulmonary, bilateral hilar, and subcarinal stations was observed with calcifications.

ema, and sepsis with acute renal failure was made. The patient underwent intermittent hemodialysis and was managed with oxygen, medium-chain fatty acid-based diet, intravenous fluids, weightbased anti-TB treatment (ATT) modified for renal failure, fluconazole, and deep venous thrombosis and stress ulcer prophylaxis. Surgery of the right trapped lung was postponed because of renal failure. His renal function gradually normalized, and the pleural drainage significantly reduced, with complete lung expansion by the second week. The intercostal drain was removed. His course was complicated by ATT-induced hepatotoxicity, necessitating initiation of levofloxacin, streptomycin, and continuation of ethambutol. He was subsequently rechallenged successfully with isoniazid and rifampicin and completed 9 months of TB treatment with clinical and radiological improvement (Fig. 1, right). He remains on follow-up and has had no further symptoms at 12 months.

\section{Systematic Search of the Literature}

Two of the authors (S.R. and R.K.) independently conducted a systematic search in PubMed (National Library of Medicine, Bethesda, MD, USA) using the terms "tuberculosis" AND "chylothorax" restricted by a publication date of 1980 onwards. These articles were screened, without blinding, by title and abstract review to identify relevant studies. Any discrepancy was resolved by consensus. This was further supplemented by a search in the Indian medical search engine IndMed, references from the retrieved articles, our personal records, and the Internet search engine Google. Full texts or abstracts were then retrieved to identify the spectrum of clinical features of chylothorax associated with TB. Articles identified in languages other than English were translated into English before data abstraction. If either the abstract or the full text was inaccessible, the corresponding author was contacted by mail requesting access to the published report. Only those articles that included patients who fulfilled the criteria (below) for chylothorax and TB as documented by the microbiologic or pathological criteria (below) were included for analysis.

TB-Associated Chylothorax
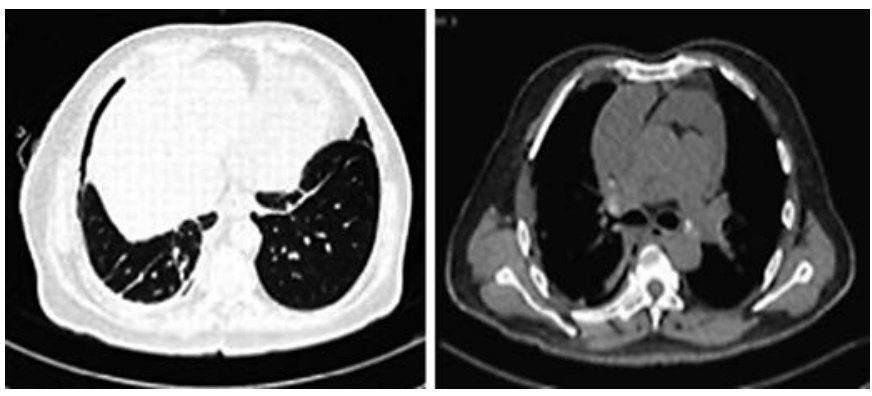

Fig. 3. Plain computed tomography images of the thorax at the level of the diaphragm indicating lack of pleural thickening and near-total lung expansion; mediastinal windows show calcified mediastinal nodes.

Chylothorax was defined by (a) the presence of chylomicrons in the pleural fluid or (b), in the absence of an evaluation for chylomicrons, pleural fluid triglyceride $>110 \mathrm{mg} / \mathrm{dL}$ and pleural fluid cholesterol $<200 \mathrm{mg} / \mathrm{dL}$ ( or a ratio of pleural fluid to serum cholesterol $<1.0$ if pleural fluid cholesterol $\geq 200 \mathrm{mg} / \mathrm{dL}$ ). TB was defined by either (a) sputum, bronchoalveolar fluid, pleural, ascitic fluid, cerebrospinal fluid, or tissue biopsy positive for acid-fast bacilli by ZN staining or (b) growth of MTB by culture in the above, or (c) caseating granulomas or miliary nodules on radiology in the presence of a compatible clinical syndrome and a response to ATT alone.

\section{Data Extraction}

The data were abstracted in a predefined data extraction form (see online suppl. Table; for all online suppl. material, see www. karger.com/doi/10.1159/000484694). From the selected cases, the following data were gathered: (a) publication details (title, authors, year of publication, journal name, and other citation details); (b) the number of cases reported in each publication; (c) the demographic details of each case, including age and gender; (d) the duration of symptoms; (e) the symptoms at presentation, including constitutional symptoms in the form of fever, anorexia, or weight loss, dyspnea, cough, chest pain, or hemoptysis; (f) the side of the effusion; (g) details on concurrent organ system involvement; (h) the time to involvement of chylothorax, if sequential; (i) comorbidities and their details, including a diagnosis of HIV; (j) pleural fluid analysis results; (k) results of microbiologic testing of pleural and sputum samples; (l) tissue biopsy results when performed for the diagnosis of TB; $(\mathrm{m})$ treatments administered, including details on steroids, ATTs, and their duration; and (n) outcome.

Informed consent was obtained from the index patient described in the paper. The institutional ethics committee approved the study.

\section{Statistical Analysis}

Continuous data are presented as mean (SD) or median (range or IQR), and categorical data as percentages and proportions. All statistical analyses were done using the statistical software SPSS IBM version 21 (PSG IMS\&R). 
Table 1. Clinical features of all patients with tuberculosis-associated chylothorax in the literature $(n=37 \text { cases })^{\mathrm{a}}$

Age $(n=35)$, years

Gender (male:female) $(n=36)$

Duration of symptoms prior to presentation $(n=29)$, months

Symptoms at presentation $(n=35)$

Constitutional

Dyspnea

Cough

Chest pain

Hemoptysis

Diagnosis concurrent $(n=36)$

Simultaneous involvement

Sequential

Time to chylothorax after diagnosis of tuberculosis $(n=10)$, weeks

\section{Clinical findings}

Chest radiography findings: effusion side $(n=37)$

Right

Left

Bilateral

Lung findings $(n=37)$

None

Consolidation

Nodular

Interstitial

Nodes $(n=37)$

None

Mediastinal

Abdominal

Both

Disseminated

Other organ involvement $(n=36)$

None

Multiple

Abdomen

Bone

Pericardium

Comorbidities $(n=37)$

Yes

No

Renal failure

Human immunodeficiency virus positive

Reported mechanism of chylothorax $(n=35)$

Mediastinal nodes

Abdominal nodes

Extensive pleural disease

Constrictive pericarditis

Spinal abscess rupture

Pleural fluid analysis

Milky appearance $(n=36)$

Yes

No

Cell count $(n=18)$

Lymphocytes

Neutrophils

Lymphocytes, \%

Protein $(n=21), \mathrm{g} / \mathrm{dL}$

Sugar $(n=14), \mathrm{mg} / \mathrm{dL}$
$39.27 \pm 4.13^{\mathrm{b}}$

$20: 16$

$1(0.75-3.00)$

$30 / 35(85.7)$

$20 / 33(60.6)$

$18 / 33(54.5)$

$10 / 33(30.3)$

$0 / 33(0)$

$26 / 36(72.2)$

$10 / 36(27.8)$

$6.75(4-9)^{\mathrm{c}}$

$17 / 37(45.9)$

$8 / 37(21.6)$

$12 / 37(32.4)$

19/37 (51.4)

$8 / 37(21.6)$

$8 / 37(21.6)$

2/37 (5.4)

$11 / 37(29.7)$

$17 / 37(45.9)$

$3 / 37(8.1)$

$4 / 37(10.8)$

$2 / 37(5.4)$

$14 / 36(38.9)$

$11 / 36(30.6)$

$5 / 36(13.9)$

$3 / 36(8.1)$

$1 / 36(2.8)$

$17 / 37(45.9)$

20/37 (54.1)

$4 / 37(10.8)$

$6 / 37(16.2)$

$18 / 35(51.4)$

$5 / 35(14.3)$

$5 / 35(14.3)$

$1 / 35(2.8)$

$2 / 35(5.6)$

$34 / 36(94.4)$

$2 / 36(5.6)$

$16 / 18(88.9)$

$3 / 18(11.1)$

$90(67-96)$

$4.70 \pm 0.37$

$107.0 \pm 11.6$ 
Table 1 (continued)

\begin{tabular}{|c|c|}
\hline $\mathrm{LDH}(n=10), \mathrm{U} / \mathrm{L}$ & $177(105-461.5)$ \\
\hline Adenosine deaminase $(n=8), \mathrm{U} / \mathrm{mL}$ & $53(35.3-87.1)$ \\
\hline Triglyceride $(n=33), \mathrm{mg} / \mathrm{dL}$ & $678(280.25-1,154)$ \\
\hline Cholesterol $(n=25), \mathrm{mg} / \mathrm{dL}$ & $72(35.5-106)$ \\
\hline Chylomicrons & $4 / 36^{\mathrm{d}}$ \\
\hline \multicolumn{2}{|c|}{ Mode of diagnosis } \\
\hline \multicolumn{2}{|c|}{ Pleural fluid AFB smear and/or NAAT positive $(n=36)$} \\
\hline Yes & $5 / 36(13.9)$ \\
\hline No & $31 / 36(86.1)$ \\
\hline \multicolumn{2}{|l|}{ Pleural fluid MTB culture positive $(n=37)$} \\
\hline Yes & $9 / 37(24.3)$ \\
\hline No & $28 / 37(75.7)$ \\
\hline \multicolumn{2}{|c|}{ Sputum or BAL AFB smear and/or NAAT positive $(n=35)$} \\
\hline Yes & $8 / 35(27)$ \\
\hline No & $27 / 35(73)$ \\
\hline \multicolumn{2}{|c|}{ Sputum/BAL AFB smear, NAAT, or sputum/BAL MTB culture positive $(n=35)$} \\
\hline Yes & $16 / 35(45.7)$ \\
\hline No & $19 / 35(54.3)$ \\
\hline \multicolumn{2}{|c|}{ Tissue diagnosis of necrotizing granulomas $(n=37)$} \\
\hline Yes & $19 / 37(51.4)$ \\
\hline No & $18 / 37(48.6)$ \\
\hline \multicolumn{2}{|c|}{ Site of tissue biopsy yielding diagnosis $(n=16)^{\mathrm{e}}$} \\
\hline Nodes & $10 / 16(62.5)$ \\
\hline Pleura & $5 / 16(31.25)$ \\
\hline Liver, marrow, spleen & $5 / 16(31.25)$ \\
\hline Lung and pericardium & $2 / 16(12.5)$ each \\
\hline \multicolumn{2}{|l|}{ Mode of diagnosis $(n=36)$} \\
\hline Microbiologic alone & $18 / 36(50)$ \\
\hline Pathologic alone & $10 / 36(27.8)$ \\
\hline Both & $8 / 36(22.2)$ \\
\hline Treatment with ATT $(n=21)$, months & $7.57(6-9)$ \\
\hline \multicolumn{2}{|l|}{ Chylothorax-specific therapy $(n=35)$} \\
\hline $\mathrm{FFD} / \mathrm{MFA}$ & $22 / 35(62.9)$ \\
\hline ICD & $22 / 35(62.9)$ \\
\hline Octreotide & $3 / 35(8.6)$ \\
\hline Duct ligation & $6 / 35(17.1)$ \\
\hline Steroids & $8 / 35(22.9)$ \\
\hline \multicolumn{2}{|l|}{ Outcome $(n=36)$} \\
\hline Alive & $34 / 36(94.4)$ \\
\hline Dead & $2 / 36(5.6)$ \\
\hline
\end{tabular}

Values are presented as mean $\pm \mathrm{SE}$, median (IQR), or $n /$ total $n(\%)$. AFB, acid-fast bacilli by Ziehl-Neelsen staining; ATT, anti-tuberculosis therapy; BAL, bronchoalveolar lavage; FFD, fat-free diet; ICD, intercostal tube drainage; IRS, immune reconstitution syndrome; MFA, medium-chain fatty acids; MTB, Mycobacterium tuberculosis; NAAT, nucleic acid amplification test. ${ }^{a}$ Includes the current case in the analysis. ${ }^{\mathrm{b}} 6 / 37(17.1 \%) \leq 16$ years. ${ }^{\mathrm{c}} 6 / 36$ (16.7\%) with IRS. ${ }^{\mathrm{d}} 11.1 \%$ positive. ${ }^{\mathrm{e}}$ More than one reported in some.

\section{Results}

We identified 37 reports of chylothorax associated with TB in 36 case reports, including the present case (see online suppl. Table) [6-40]; we excluded 8 reports containing 12 cases [41-49] because neither the full texts nor abstracts were available, as well as another 5 reports with
5 cases because there was no microbiologic or pathologic evidence of TB [50-54]. The cases where full information was not available were treated as "missing data." There were 20 males and 16 females with a mean age of $39.27 \pm$ 4.13 years; $13.9 \%(5 / 36)$ were children $[15,22,23,26]$. The patients had had symptoms for a median of 1 month (range 0.1-24 months) prior to presentation to the hos- 
Table 2. Causes of chylothorax and expected frequencies

\begin{tabular}{|c|c|}
\hline $\begin{array}{l}\text { Traumatic chylothorax } \\
\text { Noniatrogenic (blunt trauma to chest or vertebrae; knife wound to chest/gunshot wound; } \\
\text { childbirth; forceful emesis) } \\
\text { Iatrogenic (thoracic surgery [esophagectomy, congenital heart disease, lung/mediastinal } \\
\text { resections]; head and neck surgery; radiation; pacemaker; central line; embolization of } \\
\text { arteriovenous malformations) }\end{array}$ & $\approx 50 \%$ \\
\hline $\begin{array}{l}\text { Nontraumatic chylothorax } \\
\text { Malignancy (lymphomas [non-Hodgkin or Hodgkin]; other solid tumors) and other } \\
\text { miscellaneous diseases (lymphangioleiomyomatosis; filariasis; sarcoidosis; } \\
\text { amyloidosis; tuberculosis; superior vena cava obstruction; constrictive pericarditis; } \\
\text { hemangiomatosis [Gorham's disease]/lymphangiomatosis; cardiac failure; } \\
\text { transdiaphragmatic movement in cirrhosis) }\end{array}$ & $\approx 15-20 \%$ \\
\hline Idiopathic & $\approx 6 \%$ \\
\hline
\end{tabular}

pital (Table 1). Constitutional symptoms in the form of fever, anorexia, and weight loss $(85.7 \% ; 30 / 35)$, dyspnea $(60.6 \% ; 20 / 33)$, cough $(54.5 \% ; 18 / 33)$, and chest pain $(30.3 \% ; 10 / 33)$ were the most common symptoms at presentation. Close contact with a source of pulmonary TB $[22,23,30]$ or a prior history of TB $[6,12,31]$ was reported by $8.3 \%(3 / 36)$ of the patients each.

Forty-six percent (17/37) of all chylothoraces developed in patients with TB associated with comorbidities; $16.2 \%(6 / 37)$ were in association with HIV infection [12, $23,25,26,33,38]$. A very high proportion also had disseminated TB at diagnosis $(45.9 \% ; 17 / 37)$, including miliary TB in $18.9 \%(7 / 37)$ [14, 18, 26, 32, 33, 35, 36]. Chylothorax developed in association with chylous ascites in $10.8 \%(4 / 37)$ of the cases $[14,26,35,38]$. Chylothorax developed on the right side or bilaterally in the majority of cases $(78.3 \%$; 29/37). Accompanying parenchymal infiltrates and lymphadenopathy were seen in $48.6 \%(18 / 37)$ and $70.3 \%(26 / 37)$ of the cases, respectively, leading to suspicion of associated TB. However, 45.9\% (17/37) of the cases did not have any thoracic infiltrate or mediastinal adenopathy, including $13.5 \%(5 / 37)$ that presented with tubercular empyema alone $[10,21,27,29,31]$. The mechanism of development of chylothorax in association with TB was presumed to be due to interruption of lymphatic flow by mediastinal nodes in $51.4 \%(18 / 35)$, abdominal nodes in $14.3 \%(5 / 35)$, extensive pleural disease in $14.3 \%(5 / 35)$, constrictive pericarditis in $2.8 \%(1 / 35)$ [19], and erosion of a spinal abscess into the thoracic duct in $5.6 \%(2 / 35)$ of the cases $[8,12]$. The diagnosis of TB was made concurrently with the diagnosis of chylothorax in $72.2 \%(26 / 36)$ of the cases. Chylothorax developed subsequent to a diagnosis of TB on ATT in 27.8\% (10/36) of the cases at a median of 6.75 weeks (IQR 4-9) following the initiation of treatment $[7,12-14,25,26,32,36,38,40]$. Chylothorax occurred along with an immune reconstitution syndrome (IRS) in $6(60 \% ; 6 / 10)$ of these cases [12, $25,26,32,36,40]$, including 3 in immunocompetent individuals $[32,36,40]$.

The vast majority of chylothoraces were suspected because of a milky appearance of the pleural fluid (94.4\%). Pleural fluid analysis showed exudative effusion in all cases described (mean protein $4.70 \pm 0.37 \mathrm{~g} / \mathrm{dL}$; median LDH $177 \mathrm{U} / \mathrm{L})$. About $88.9 \%$ of the effusions were lymphocytic predominant, with a median of $90 \%$ lymphocytes (IQR 67-97). The median triglyceride value observed was very elevated at $678 \mathrm{mg} / \mathrm{dL}(280.25-1,154)$. Consequently, chylomicrons were reported in only $11.1 \%(4 / 36)$ of the cases, including the index case $[9,24,40]$.

The diagnosis of TB was established microbiologically in $72.2 \%(26 / 36)$ of the cases, with a positive pleural fluid or sputum, bronchoalveolar lavage, gastric aspirate, or tissue mycobacterial culture, or a positive nucleic acid amplification test. Tuberculous empyema was associated with chylothorax in $25 \%$ (9/36) of the cases, including the index case $[10,13,21,24,27-29,31,35]$. Pathologic biopsies of the involved organ alone established the diagnosis of TB in a further $27.8 \%(10 / 36)[6,7,16,18-20,31,34$, 37, 39].

ATT was administered for a median of 7.57 months (IQR 6-9). A fat-free or medium-chain fatty acid diet was administered in $62.9 \%(22 / 35)$ of the cases. Steroids were given in $22.9 \%(8 / 35)$ of the cases, often for suspected IRS (37.5\% [3/8]) or endobronchial TB. Chylothorax increased or developed on ATT alone in 25\% (9/36) of the cases, including in $16.7 \%(6 / 36)$ with IRS. However, tho- 
racic duct ligation $[12,14,20,24,36,40]$ and octreotide $[22,26,36]$ were required in only $17.1 \%(6 / 35)$ and $8.6 \%$ $(3 / 35)$ of the cases, respectively. In all, $94.4 \%(34 / 36)$ of the cases had good resolution of chylothorax and completed treatment successfully; only $5.6 \%(2 / 36)$ died [18, 27].

\section{Discussion}

A wide variety of etiologies can cause nontraumatic chylothorax (Table 2). In a large series of patients with chylothorax $(n=203)$, none were reported to have chylothorax due to TB [55]. Our systematic review suggests that chylothorax is a very rare but well-described complication of TB [6-40]. The occurrence of an acute effusion with smooth unthickened pleural surfaces along with demonstration of elevated triglyceride $(\geq 110 \mathrm{mg} / \mathrm{dL})$ and low cholesterol levels (pleural/serum cholesterol $<1$ ) or demonstration of chylomicrons by lipoprotein electrophoresis differentiates a chylothorax from a pseudochylothorax [3]. The absence of long-standing pleural effusion prior to the current illness and clear biochemical evidence and definitive demonstration of chylomicrons along with radiological features suggestive of $\mathrm{TB}$ and microbiologic demonstration of MTB established the association of chylothorax with TB in the index case. Pleural thickening was due to TB and Candida albicans-related empyema; it has been reported earlier in association with TB-chylothorax [31, 40].

Several mechanisms have been described for the development of chylothorax in TB. These include (1) mediastinal adenopathy with occlusion or erosion into the thoracic duct and leakage of chyle into the pleural space, (2) abdominal lymphadenopathy with occlusion of the cisterna chyli and opening of lymphaticovenous anastomosis, and (3) constrictive pericarditis associated with elevated left subclavian venous pressures leading to increased production and reduced drainage of lymph. The observation of exudates in all cases of TB-related chylothorax reported in the present systematic review, however, suggests a direct involvement of the pleura and/or lymphatic ducts due to TB or host-immune responses as the primary cause in most patients. Other mechanisms are also evident from this systematic review; these include erosion of the thoracic duct by spinal abscesses, extensive pleural disease with lymphatic exudation, and duct damage due to IRS. The occurrence of chylothorax subsequent to initiation of ATT in 27.8\% (10/36) of the patients, the absence of any associated mediastinal or ab- dominal adenopathy in $35 \%$, the very high proportion of cases with disseminated TB $(45.9 \% ; 17 / 37)$ in apparently immunocompetent individuals presenting with chylothorax, including miliary TB $(18.9 \%$; $7 / 37)$, and the development of chylothorax during immune reconstitution suggest direct or host-immune damage to the thoracic duct as a major mechanism for the development of chylothorax. The median time to development of chylothorax observed in our systematic review was 6.75 weeks (IQR 4-9), which is the most common time period of immune reconstitution; IRS can occur in $2.4-28 \%$ of immunocompetent individuals with lymph nodal [40] or pulmonary TB [56].

The occurrence of chylothorax was suspected due to obvious milky pleural fluid, suggesting an underrecognition of chylothorax in TB. Tuberculous empyema was associated with chylothorax in $25 \%(9 / 36)$ of the cases, including $13.9 \%(5 / 36)$ where this was the sole manifestation. Given the disseminated paucibacillary disease in a significant majority, biopsies of involved tissues like nodes and the pleura were needed in 50\% (18/36) of the cases, with $22.2 \%$ (10/36) being diagnosed only by pathology. Lymphangiograms were reported only for $8.6 \%$ $(3 / 35)[6,14,37]$, and the site and cause of leakage of chyle was presumptive in most reported cases.

Steroids were administered in $22.9 \%$ (8/35) of the cases for IRS, bronchial stenosis, and severe disseminated TB with variable responses in reduction of chylothorax. The need for thoracic duct interruption was reported only for $17.1 \%(6 / 35)$ of the cases, with success in $83.3 \%(5 / 6)$ of these, indicating that chylothorax may resolve with a fatfree diet and ATT in the majority of cases. TB-chylothorax is associated with good prognosis with conservative treatment despite the higher proportion with disseminated disease at diagnosis and associated comorbidities. The survival rate was $94.4 \%$.

\section{Conclusions}

Chylothorax is a very rare but well-described complication of TB. It develops with extensive mediastinal or abdominal lymphadenopathy and extensive pleural disease, but it may also develop without any obvious lymphadenopathy and as part of an IRS. ATT and dietary manipulation - followed by duct ligation if needed in a small minority of cases - are associated with good outcome and low mortality. 


\section{Acknowledgements}

The authors would like to thank R. Jagadeshwari, research coordination, PSG Institute of Pulmonology, for her help in rechecking the tables of the systematic review and proofreading the manuscript. The authors also thank the Senior Librarian, PSG IMS\&R, for help in procuring previously published manuscripts.

\section{Author Contributions}

All authors were responsible for patient care and initiated manuscript preparation. S.R. and R.K. performed the systematic review, retrieving the articles of our systematic search and abstracting data. S.R. and R.K. take responsibility for the content of the paper, including the data and analysis.

\section{Financial Disclosure and Conflicts of Interest}

No funding was utilized for this manuscript and the authors have no conflicts of interest to disclose.

\section{References}

1 Arinaminpathy N, Batra D, Khaparde S, Vualnam T, Maheshwari N, Sharma L, Nair SA, Dewan P: The number of privately treated tuberculosis cases in India: an estimation from drug sales data. Lancet Infect Dis 2016; 16:1255-1260.

2 WHO: Global Tuberculosis Report 2016. 2016. http://apps.who.int/medicinedocs/documents/s23098en/s23098en.pdf.

3 Hillerdal G: Chylothorax and pseudochylothorax. Eur Respir J 1997;10:1157-1162.

$\checkmark 4$ Romero S: Nontraumatic chylothorax. Curr Opin Pulm Med 2000;6:287-291.

5 Ferrer J: Pleural tuberculosis. Eur Respir J 1997;10:942-947.

6 Vennera MC, Moreno R, Cot J, Marin A, Sanchez-Lloret J, Picado C, Agusti-Vidal A: Chylothorax and tuberculosis. Thorax 1983;38: 694-695.

7 Zafar A, Gul M, Zaman R: Chylothorax. J Ayub Med Coll Abbottabad 1988;3:27-28.

-8 Menzies R, Hidvegi R: Chylothorax associated with tuberculous spondylitis. Can Assoc Radiol J 1988;39:238-241.

9 Haro M, Ruiz J, Álvarez J, Gallego M: Quilotórax tuberculoso. Enferm Infecc Microbiol Clin 1994;12:417-418.

10 Antón PA, Rubio J, Casán P, Franquet T: Chylothorax due to Mycobacterium tuberculosis. Thorax 1995;50:1019.

-11 Deniel F, Rabbat A, Laaban JP: Spontaneous bilateral chylothorax revealing disseminated tuberculosis complicated by massive pulmonary embolism (in French). Rev Mal Respir $1999 ; 16: 836-838$

>12 Singh S, Girod JP, Ghobrial MW: Chylothorax as a complication of tuberculosis in the setting of the human immunodeficiency virus infection. Arch Intern Med 2001;161:2621.

-13 Prasad RS, Fraser MH, Urquhart GD, McLean AN: Rupture of tuberculous spinal abscess resulting in tuberculous empyema and chylothorax. Spinal Cord 2003;41:410-412.

-14 Tomić I, Plavec G, Karlicić V, Spasić V, Rusović S, Stanić V, Cvijanović V, Ristanović A: Chylous effusions (in Serbian). Vojnosanit Pregl 2003;60:613-620.
15 Gie RP, Goussard P, Kling S, Schaaf HS, Beyers N: Unusual forms of intrathoracic tuberculosis in children and their management. Paediatr Respir Rev 2004;5(suppl A):S139S141.

16 Gupta D, Maheshwari U, Aggarwal AN: Tuberculosis chylothorax. Lung India 2004;21: 54-55.

17 Chen HA, Cheng NC, Lin KP, Liao HT, Chen $\mathrm{CH}$, Huang DF: Mononeuropathy multiplex and chylothorax as earlier manifestations of pulmonary tuberculosis. J Intern Med 2005; 257:561-563.

18 Saumoy M, Mirón M, Oltra C, Vidal F, Richart C: Tuberculous chylothorax: case report and review of the literature (in Spanish). An Med Interna 2005;22:238-240.

19 Singh P, Shah KV, Shah NT, Chauhan JB, Shah B, Jindal S, Gami S: Chylothorax: a rare presentation of constrictive pericarditis. Indian J Tuberc 2005;52:207-210.

20 Baig F, Khan SG, Warind J: Tuberculous chylothorax. Chest DOI: 10.1378/chest.130.4 MeetingAbstracts.304S-a.

21 Büyükşirin M, Konya A, Polat G, Ürpek G, Tibet G: Case of chylothorax due to Mycobacterium tuberculosis. Toraks Dergisi 2006;7: 216-217.

22 Cakir E, Gocmen B, Uyan ZS, Oktem S, Kiyan G, Karakoc F, Ersu R, Karadag B, Dagli T, Dagli E: An unusual case of chylothorax complicating childhood tuberculosis. Pediatr Pulmonol 2008;43:611-614.

23 Grobbelaar M, Andronikou S, Goussard P, Theron S, Mapukata A, George R: Chylothorax as a complication of pulmonary tuberculosis in children. Pediatr Radiol 2008;38:224226.

24 Karapolat S, Sanli A, Onen A: Chylothorax due to tuberculosis lymphadenopathy: report of a case. Surg Today 2008;38:938-941.

25 Lin JN, Lai CH, Chen YH, Chang LL, Lee SS, Lin $\mathrm{HH}$ : Immune reconstitution inflammatory syndrome presenting as chylothorax in a patient with HIV and Mycobacterium tuberculosis coinfection: a case report. BMC Infect Dis 2010;10:321.
26 Rabie H, Lomp A, Goussard P, Nel E, Cotton M: Paradoxical tuberculosis associated immune reconstitution inflammatory syndrome presenting with chylous ascites and chylothorax in a HIV-1 infected child. J Trop Pediatr 2010;56:355-358.

27 Hijazi EM, Hamouri S: Post-coronary artery bypass grafting chylothorax with tuberculous empyema thoracis. Am J Case Rep 2011;12: 184-185.

28 Kant S, Verma SK, Anand SC, Prasad R, Verma RK: Development of bilateral chylothorax in a younger female secondary to tuberculosis. Lung India 2011;28:56-59.

29 Ananthan VS, Siva KK: A rare case of acid-fast bacilli in chylothorax. Lung India 2012;29: 166-168.

30 Tan GP, Tai DYH, Nallakaruppan VDO: A case of chylothorax. Chest DOI: 10.1378/ chest. 1383008 .

31 Yasaratne BMGD, Madegedara RMD: Chylothorax; a description of four cases and a brief review. J Ceylon Coll Phys 2012;43:49-53.

32 Ip H, Schomberg LE, Ahmed L: Pleural effusions in a patient with tuberculosis on dialysis. Lancet 2013;382:570

33 Bielsa S, Pardina M, Porcel JM: Chylothorax due to enlarged tuberculous lymph nodes. BMJ Case Rep 2014;2014:bcr2014204582.

34 Hamad WB, Amar JB, Dhahri B, Baccar MA, Azzabi S, Aouina H, Bouacha H: Spontaneous chylothorax revealing a mediastinal and abdominal lymph node tuberculosis. Eur Respir J 2014;44(suppl 58):P2648.

35 Kim KJ, Park DW, Choi WS: Simultaneous chylothorax and chylous ascites due to tuberculosis. Infect Chemother 2014;46:50-53.

36 Akthar M, Lardizabal A, Patrawalla AS, Emeh OK, Bolanowski PJ, Mangura B: Disseminated tuberculosis complicated by chylothorax. American Thoracic Society International Conference, May 15-20, 2015, abstract A3259. https://cms.psav.com/cPaper2015/myitinerary/session -11780. html? congress=ats 2015 . 
37 Kutlu O, Demirbas S, Sakin A: Chylothorax due to tuberculosis lymphadenitis. North Clin Istanb 2017;3:225-228.

38 Del Cueto-Aguilera Á, Ibarra-Sifuentes H, Delgado-García G, Atilano A, Galarza-Delgado D: Chylothorax and chylous ascites due to Mycobacterium tuberculosis in an AIDS patient whose PCR tested negative. Pneumologia 2016;65:161-163.

39 Amar JB, Zaibi H, Dahri B, Aouina H: Spontaneous chylothorax revealing a mediastinal and abdominal lymph node tuberculosis. Indian J Tuberc 2017;64:141-143.

40 Duraikannan P, Saheer S, Balamugesh T, Christopher DJ: Rare cause of paradoxical worsening of pleural effusion in a patient with tuberculosis. Lung India 2017;34:167-169.

41 Brandt M: Ein Beitrag zur Kasuistik der Ductus Thoracicus-Tuberkulose und des Chylothorax; Inaug Diss Heidelberg, Heidelberg, Universitäts-Buchdruckerei von J Horning, 1917.

42 Kaplan M, Grumbach R, Grenier B: A case of right chylothorax during tuberculous primary infection (in French). Arch Fr Pediatr 1953; 10:1060-1065.

43 Mas Ramos A: Chylothorax and primary tuberculosis infection; brief summary of the clinical entity of chylothorax and case report (in Spanish). Rev Esp Tuberc 1954;23:123130.
44 Bujko K, Kruc S, Michalowicz R: Pleural chylothorax in a child with lymph node tuberculosis (in Polish). Pediatr Pol 1964;39:961-964.

45 Leutke HJ, Sendel A: Chylothorax due to erosion of the thoracic duct in lymph node tuberculosis (in German). Med Welt 1966;40: 2117-2120.

46 Kovarik JL: Spontaneous right chylothorax with middle lobe syndrome. Report of a case. Dis Chest 1967;52:261-263.

47 van der Heijden AH, Hamersma WB: Chylothorax as a rare complication in tuberculosis (in Dutch). Ned Tijdschr Geneeskd 1984;128: 2260-2262.

48 Li LY, Zhao QX, Luo WC: An analysis of 30 cases of chylothorax and chyloperitoneum (in Chinese). Zhonghua Nei Ke Za Zhi 1991;30: 347-349, 382.

49 El Hammoumi MM, Drissi G, Achir A, Benchekroun A, Kabiri EH, Benosman A: Spontaneous bilateral chylothorax revealing a mediastinal and abdominal lymph node tuberculosis (in French). Rev Pneumol Clin 2014;70:173-176
50 Menon RK, Aziah M, Kuppusamy I: Chylothorax secondary to tuberculosis. Med J Malaysia 1995;50:425-426.

51 Anwar S, Rahman AKMM, Rahman ME, Mollah AH, Matin A, Bilqis L: Bilateral chylothorax due to disseminated tuberculosis and acute lymphoblastic leukemia in a young boy: a case report and literature review. Bangladesh J Child Health 2014;38:164-168.

52 Naeem M, Sobani ZA, Zubairi A, Fatmi S, Khan JA: Constrictive pericarditis presenting as chylothorax. Singapore Med J 2011;52: e187-e189.

53 Summachiwakij S, Tungsubutra W, Koomanachai P, Charoenratanakul S: Chylous ascites and chylothorax due to constrictive pericarditis in a patient infected with HIV: a case report. J Med Case Rep 2012;6:163.

54 Büyükşirin M, Polat Gl, Usalan A, Aydoğdu $\mathrm{Z}$ : Chylothorax and sarcoidosis: case report. Tur Toraks Der 2011;12:117-119.

55 Doerr CH, Allen MS, Nichols FC 3rd, Ryu JH: Etiology of chylothorax in 203 patients. Mayo Clin Proc 2005;80:867-870.

56 Rajagopala S, Chandrasekharan S: Severe $M y$ cobacterium tuberculosis-related immune reconstitution syndrome in an immunocompetent patient. Indian J Crit Care Med 2015; 19: $50-52$. 